\section{LOS PAISAJES CULTURALES DE UNESCO DESDE LA PERSPECTIVA DE AMÉRICA LATINA Y EL CARIBE. CONCEPTUALIZACIONES, SITUACIONES $Y$ POTENCIALIDADES ${ }^{1}$}

Rocío Silva Pérez y y Víctor Fernández Salinas ${ }^{3}$

\section{Resumen}

Los paisajes patrimoniales son un campo emergente en el debate científico y los paisajes culturales de la Lista del Patrimonio Mundial son un interesante objeto de reflexión, puesto que poseen un relevante reconocimiento internacional y representan una categoría en expansión de esta Lista. América Latina y El Caribe, como región de Unesco, tiene una presencia en la Lista relativamente por debajo de lo que significaría un registro representativo de bienes culturales en la escala planetaria. Ambas circunstancias constituyen oportunidades para acrecentar sus paisajes culturales en la Lista, y, sobre todo, para profundizar en el conocimiento y valoración de una figura que sintetiza el acervo

\section{THE CULTURAL LANDSCAPES OF UNESCO FROM THE LATIN AMERICAN AND THE CARIBBEAN PERSPECTIVE. CONCEPTUALIZATIONS, SITUATIONS AND POTENTIALS ${ }^{1}$}

Rocío Silva Perez ${ }^{2}$ and Víctor Fernández Salinas ${ }^{3}$

\section{Abstract}

Cultural landscapes are an emerging field in the scientific debate on landscapes. In this regard, the cultural landscapes included in the World Heritage List are interesting objects of reflection since they possess relevant international recognition and represent an expanding category in this list. Latin America and the Caribbean, as a Unesco region, have a relatively low presence in this List in terms of cultural capital at a global scale. These circumstances provide opportunities to increase the number of cultural landscapes on this list and, most notably, expand the knowledge and appreciation of a figure that both synthesizes 
patrimonial de una comunidad y se erige en una potencialidad para el desarrollo territorial y el incremento de la calidad de vida de las poblaciones. Este artículo analiza la Lista de Unesco y la situación de América Latina y el Caribe respecto a ella, repasa los procedimientos y posibilidades para la inscripción de nuevos paisajes culturales en la citada Lista y esboza algunos patrones que ayuden a avanzar en la complejidad de la gestión de estos paisajes.

\section{PALABRAS CLAVE: PATRIMONIO MUNDIAL; PAISAJES CULTURALES}

Fecha recepción: 01-05-2014

Fecha aceptación: 05-06-2015

1 Este artículo se inserta en un programa de investigación sobre paisajes patrimoniales desarrollado a través de dos proyectos: I + D+l del Ministerio de Economía y Competitividad del Gobierno de España Paisajes patrimoniales de España (código CS0201239564-C07-07) y Proyecto de Excelencia de la Junta de Andalucía Métodos e instrumentos para el reconocimiento de paisajes patrimoniales de Andalucía (código P12-SEJ-2024).

2 España. Doctora en Geografía y profesora del Departamento de Geografía Humana de la Universidad de Sevilla. Correo electrónico: rsilva@us.es

3 España. Doctor en Geografía y profesor titular de la Universidad de Sevilla. Correo electrónico: salinas@us.es the heritage background of a community and paves the way for land development and the increase in the quality of life of those involved. This paper analyzes the Unesco List and the situation of Latin America and the Caribbean, reviews the procedures and possibilities for the registration of cultural landscapes and outlines some patterns intended to provide deeper insights into the complexity related to the management of these landscapes.

\section{KEYWORDS: WORLD HERITAGE; CULTURAL LANDSCAPES.}

Received: 01-05-2014

Accepted: 05-06-2015

1 This paper is part of a research program on cultural heritage conducted through two projects: "Heritage Landscapes in Spain" (CS02012-39564-C07-07) R+D+l project funded by the Ministry of Economy and Competitiveness and "Methods and Instruments for the Recognition of Heritage Landscapes in Andalusia (P12-SEJ-2024) Excellence Project funded by the Government of Andalusia.

2 Spain. PhD in Geography. Professor, Department of Human Geography at the University of Seville. Email: rsilva@us.es

3 Spain. PhD in Geography. Professor, University of Seville. Email: salinas@us.es 


\section{Introducción}

\section{POR QUÉ LA MIRADA A LOS PAISAJES DESDE LA PERSPECTIVA PATRIMONIAL}

La identificación, conocimiento y activación de los bienes patrimoniales con que cuentan los territorios constituye un tema recurrente en investigaciones y políticas gubernamentales. El patrimonio concreta en el espacio la herencia recibida y expresa la idiosincrasia cultural de una comunidad ${ }^{4}$. Su conocimiento refuerza la autoestima de las comunidades locales y esto redunda en beneficio de su preservación y de una mayor sostenibilidad general del orden territorial ${ }^{5}$. Los bienes culturales son recursos específicos y no deslocalizables: están anclados en los territorios ${ }^{6}$; y, en el actual contexto de globalización socioeconómica y de estandarización cultural, se considera que su movilización favorece el dinamismo social, económico y cultural, contribuyendo además a la generación de empleo.

El debate en torno al análisis e identificación de los recursos culturales territoriales no puede desligarse de la evolución operada en el entendimiento del propio patrimonio ${ }^{7}$. Por un lado, porque cambia su

Castillo, 2009.

Ojeda, 2013.

Alonso, 2014

7 Martínez de Pisón, 2013. sentido más profundo al trasladar el protagonismo del objeto (la materialidad del bien), al sujeto (la sociedad que lo crea, significa y disfruta); por otro, porque la noción de patrimonio ha experimentado una profunda ampliación semántica hasta abarcar elementos cotidianos antes poco valorados. En paralelo, los bienes naturales se patrimonializan y los tradicionales patrimonios histórico-cultural y ambiental-naturalístico se acercan y confunden, hasta el punto de considerar que los bienes patrimoniales (culturales o naturales), en cuanto implican apropiación y asignación social de valores, están mediatizado por la cultura y son, en consecuencia, patrimonio cultural.

El interés por los recursos patrimoniales trasciende la perspectiva académica y alcanza la esfera gubernamental. Los estados, regiones y municipios muestran interés por el refrendo institucional de los bienes patrimoniales de sus territorios; ello con distintos fines: preservación, concienciación, reclamo turístico, atracción de empresas, generación de empleo, desarrollo territorial. En un primer momento, esto se consigue a través de normas y figuras estatales y/o regionales (parques nacionales, monumentos, conjuntos históricos y otros); pero en un contexto de ampliación de flujos, en el que la marca patrimonial de los territorios se difunde y compite en la escala planetaria, las distinciones 
de rango internacional adquieren un protagonismo creciente. Entre ellas destaca la Lista de Patrimonio Mundial (en adelante, Lista ${ }^{8}$ ), producto de la Convención para la Protección del Patrimonio Natural y Cultural (en adelante, Convención ${ }^{9}$ ).

Surge así un ambiente favorable para la expansión de una figura híbrida como la de los paisajes patrimoniales: aquellos que deben ser protegidos en razón de valores naturales o/y culturales tal y como los perciben sus habitantes. El paisaje patrimonial adquiere pues creciente relevancia y ofrece posibilidades para aunar patrimonio y desarrollo en beneficio de las comunidades locales. Ser paisaje cultural de la Lista ofrece oportunidades para el desarrollo de los territorios; pero también implica compromisos relacionados con la preservación de los bienes e importantes retos, entre ellos una gestión acertada que atienda a la diversidad y complejidad de los paisajes y a las necesidades de los territorios.

\section{POR QUÉ AMÉRICA LATINA Y EL CARIBE}

El citado debate sobre patrimonio se ha intensificado en los últimos años en América Latina y El Caribe ${ }^{10}$. Su diversidad geográfica, su riqueza

8 Unesco, 2013a.

9 Unesco, 1972.

10 América Latina y El Caribe es una de las cinco regiones en las que Unesco divide el planeta a efectos de sus políticas.

184 revista invi № 85 / Noviembre 2015 / Volumen № 30: 181-214 natural y sus particularidades históricas sustentan un patrimonio considerable, aunque relativamente poco reconocido ${ }^{11}$. La utilización de los recursos naturales y/o culturales como reclamo turístico tiene aquí una amplia tradición, sobre todo en el Caribe, donde llega a representar más del 25\% del PIB. Pero no existe una confluencia de intereses entre turismo, patrimonio y desarrollo, ya que la especialización turística basada en la disponibilidad sol y playas ha generado graves impactos territoriales y ambientales; y el modelo territorial implementado-con enclaves culturalmente despatrimonializados y desanclados de los territorioses netamente neocolonial y revierte poco en las comunidades locales. Hasta los nombres de algunos de estos lugares, como la Riviera Maya, apuntan a esta circunstancia. En estos destinos el patrimonio es sólo una oferta complementaria, tal y como reconoce el primer Informe Periódico sobre el Estado del Patrimonio Mundial en América Latina y el Caribe $^{12}$. Tras el diagnóstico sobre la presencia de la región en la Lista, sus redactores hacen hincapié en aspectos que es necesario corregir; entre ellos, la escasa representación de algunas subregiones (como el Caribe) y de categorías (como la de paisaje cultural), o el desconocimiento en la región,

\footnotetext{
11 Hernández; Rotman y González, 2010; Mujica, 2000; Rössler, Lepeigné-Cobo y Ríos, 2000.

12 Unesco, 2004.
} 
tanto de la nomenclatura de Unesco, como de los protocolos para incorporar bienes a la Lista.

Pasado un decenio, han sido numerosas las reuniones y eventos celebrados para subsanar tales deficiencias. Así, en el mismo 2004 el Comité de Patrimonio Mundial (en adelante Comité), que es el órgano responsable del seguimiento de la Convención y de la Lista, decidió la creación de un Programa de Desarrollo de Capacidades para El Caribe, aún vigente. En 2008 el Iccrom inició un Programa para la Conservación del Patrimonio en América Latina y El Caribe (LATAM), dirigido a la capacitación de gestores patrimoniales. Respecto a los paisajes culturales, el Instituto de la Patagonia de la Universidad de Magallanes (Chile) viene desarrollando desde 2010 encuentros anuales sobre esta figura de Unesco; y en Cartagena de Indias se celebró en noviembre de 2012 el II Encuentro de Paisajes Culturales, donde se aprobó la Carta Iberoamericana de Paisaje Cultural ${ }^{13}$.

\section{OBJETIVOS Y FUENTES}

Como planteamiento básico de este trabajo, se mantiene que la figura de paisaje cultural puede resultar especialmente adecuada para incorporar nuevas declaraciones en la región de América Latina y el Caribe y para redefinir algunos de

13 Carta iberoamericana \& 2012. los bienes mixtos que ya están en la Lista. Con todo, sus autores no creen que aumentar la presencia de bienes en esta Lista constituya en sí una acción positiva o deseable, ni siquiera que esto asegure una mejor protección y valorización; la experiencia ofrece demasiadas excepciones. Sí estiman, en cambio, que el reconocimiento de paisajes de América Latina y El Caribe como paisajes culturales Patrimonio Mundial redundará en una mayor atención política y técnica a la protección del paisaje en general, y no sólo de los incluidos en esta Lista; y que también puede redundar en pro del desarrollo socioeconómico de los territorios, siempre y cuando se establezca una gestión acertada de tales bienes. Esta línea es la que orienta este artículo y no la del simple apoyo al incremento y consagración de unos bienes culturales que son igual de importantes tengan, o no, el reconocimiento de Unesco.

\section{LOS OBJETIVOS ESPECÍFICOS SON:}

- Repensar el concepto de paisajes patrimoniales, con especial atención a la forma en que Unesco define los paisajes culturales.

- Revisar la política actual de Unesco respecto a la Lista y la manera en que ésta puede afectar a las candidaturas de Latinoamérica y El Caribe. 
- Analizar la distribución territorial actual en esta región de los bienes incluidos en la Lista, con especial mención de los paisajes culturales

- Identificar claves para la selección de paisajes culturales de América Latina y El Caribe con posibilidades de ser incluidos en la Lista. Debe subrayarse que la intención de este artículo no es la selección directa de estos paisajes, sino proporcionar información que oriente esta labor que debe acometerse por los estados-parte.

- Subsidiariamente también se persigue el apunte de algunas claves para la gestión de los paisajes culturales de la Lista; un aspecto particularmente complejo que requeriría un análisis omnicomprensivo que está todavía por hacer y que sobrepasa los cometidos de este trabajo.

Con relación a las fuentes, en la parte final de este artículo se aporta el repertorio de los recursos bibliográficos y documentales consultados. A todos los efectos ha sido básico el portal del Centro del Patrimonio Mundial ${ }^{14}$, en el que existe una profusa, aunque no siempre clara, información referente a la Lista. Otros portales útiles para el trabajo fueron los de las principales instituciones asesoras

14 Portal del Centro del Patrimonio Mundial: www.whc.org. de Unesco, especialmente el de Icomos (Consejo Internacional de Monumentos y Sitios) ${ }^{15}$.

\section{Paisajes patrimoniales, paisajes culturales. Revisión conceptual}

La ampliación en el entendimiento conceptual y territorial del patrimonio durante los últimos años se acompaña de una revisión profunda de lo que se entiende por paisaje ${ }^{16}$. La vinculación de dos sustantivos polifacéticos, cambiantes y, a veces, asimilables-patrimonio y paisaje-da lugar a lo que podría llamarse un concepto de segunda generación, donde el sustantivo patrimonio cualifica -y adjetiva- al de paisaje. No obstante, no se debe pensar que la relación entre paisaje y patrimonio carece de trayectoria; al contrario, y aunque cuenta con otros precedentes, adquiere gran relevancia desde los años ochenta, en los que el trinomio territorio, paisaje y patrimonio se convierte en objeto de debate ${ }^{17}$. Al investigar los aspectos que denotan el paisaje a través de su

15 Portal de ICOMOS (Consejo Internacional de Monumentos y Sitios): www.icomos.org.

16 Galimberti, 2013.

17 Martínez de Pisón, 1983; Ortega, 1998; Maderuelo, 2010. 
materialidad y aquellos otros que lo connotan por sus valores intangibles y simbólicos, el patrimonio se convierte en un argumento clave para conocer la dimensión cultural del territorio ${ }^{18}$. "El paisaje es patrimonio de todos los ciudadanos" 19 es una frase que expresa con claridad cómo su entendimiento pasa por la apropiación socio-identitaria por parte de las comunidades que lo viven y lo sienten ${ }^{20}$. Por otro lado, el patrimonio y el paisaje se convierten en bienes básicos para la gestión sostenible de los recursos locales y para el desarrollo de los territorios $^{21}$. No menos importante ha sido el reconocimiento del paisaje como un activo turístico singular que ha permitido nuevas interpretaciones de los destinos de ocio y, sobre todo, una palanca con que reinventar discursos para hacer más atractivos aquellos espacios turísticos maduros con muestras de obsolescencia ${ }^{22}$. En todo caso, y vista la fragilidad de los paisajes patrimoniales, se ha desarrollado también una importante línea de trabajo que reflexiona sobre su protección ${ }^{23}$.

Desde mediados de los años sesenta del siglo pasado algunos sectores de la intelectualidad europea empiezan a mostrar inquietud por la preservación de los valores de los paisajes. Su resultado es la

18 Amores, 2002; Tilley, 1994.

19 IKTy Paisaia, 2005, p. 13.

20 Nogué, 2010; Priore 2002.

21 Observatorio de la Sostenibilidad en España, 2008.

22 Gros, 2002; Nogué, 1992.

23 Fernández, 2007; Luengo y Rössler, 2012. aparición de leyes y normas nacionales y regionales enmarcadas en políticas territoriales ${ }^{24}$. Un poco antes, Unesco aprueba la Recomendación relativa a la protección de la belleza y el carácter de los lugares ${ }^{25}$. En su primer artículo "se entiende por protección de la belleza y el carácter de los lugares y paisajes, la preservación y, cuando sea posible, la restitución del aspecto de los lugares y paisajes naturales, rurales o urbanos debidos a la naturaleza o a la mano del hombre que ofrecen un interés cultural o estético o que constituyen medios naturales característicos". El interés cultural por los paisajes en Unesco precede, pues, en un decenio a la Convención (1972), que dará inicio años después a la Lista; texto, sin embargo, donde el paisaje es citado sólo una vez y limitado a los conjuntos históricos. En estas aportaciones, el interés paisajístico se restringe a espacios excelsos de reconocido valor patrimonial.

El desarrollo de la Lista (inaugurada en 1978) evidencia muy pronto que las categorías seleccionadas para el patrimonio cultural (monumentos, conjuntos y lugares) no se adecuan bien a la emergencia de bienes que deben ser entendidos en escalas territoriales amplias. Desde el principio de

\footnotetext{
24 Ley federal sobre la protección de la naturaleza y el paisaje suizo, 1966; Ley federal de protección de la naturaleza y gestión del paisaje alemana, 1976; o Ley de protección y puesta en valor de los paisajes franceses, 1993.

25

Unesco, 1962.
}

revista invi № 85 / Noviembre2015 / Volumen №30: 181-214 187 
los ochenta, Unesco inicia un debate sobre la pertinencia de un cambio de consideración sobre los valores patrimoniales, entre otros, de los paisajes rurales $^{26}$; de tal forma que en 1992 la organización consagra una nueva categoría: los paisajes cultura$\operatorname{les}^{27}$. Su definición se incluye en el párrafo 39 de las Directrices prácticas para la implementación de la Convención (en adelante Directrices ${ }^{28}$ ): "lugares que combinan el trabajo de la naturaleza y el ser humano, y que son ilustrativos de la evolución de la sociedad humana y del uso del espacio a lo largo del tiempo, bajo la influencia de limitaciones físicas y/o oportunidades presentadas por el medio natural y de sucesivas fuerzas sociales, económicas y culturales". En esta definición la materialidad, los lugares, prevalece sobre la percepción.

En otra línea discursiva, desde hace casi un decenio Unesco alienta el debate sobre el paisaje urbano histórico, que es producto del Memorándum de Viena de 2005. Hasta el momento se ha concretado en una recomendación ${ }^{29}$ cuyo objetivo es sustituir, no sin profundos problemas conceptuales y meto-

26 Fowler, 2003.

27 Rössler, 2000.

28 Unesco, 2013b.

29 Unesco, 2011. dológicos, el concepto de conjunto histórico por el citado de paisaje urbano histórico ${ }^{30}$.

El debate en Unesco sobre el entendimiento del paisaje como patrimonio y la propia consideración de qué son los paisajes culturales y cómo gestionarlos dista mucho de estar concluido.

También resultan interesantes las vías que abre el Convenio europeo del paisaje ${ }^{31}$ para el reconocimiento de paisajes patrimoniales. Su definición de paisaje como "cualquier parte del territorio tal como lo percibe la población, cuyo carácter sea el resultado de la acción y la interacción de factores naturales y/o humanos" (art. 1), implica una concepción revolucionaria en el entendimiento del paisaje. Tal aseveración se sustenta, por una parte, en la asignación de la categoría paisajística a todo el territorio y no sólo a los espacios excelsos o singulares. Por otra, el Convenio confiere a los paisajes, frente a la definición de Unesco, un significado esencialmente perceptivo y valorativo que los impregna de un fuerte contenido patrimonial e identitario; lo que resulta, si cabe, más novedoso ${ }^{32}$.

30 Se entiende por paisaje urbano histórico la zona urbana resultante de una estratificación histórica de valores y atributos culturales y naturales, lo que trasciende la noción de 'conjunto' o 'centro histórico' para abarcar el contexto urbano general y su entorno geográfico, Unesco (2011).

31 Council of Europe, 2000.

32 El preámbulo del Convenio Europeo del Paisaje recoge expresamente que el paisaje es un componente fundamental del patrimonio natural y cultural europeo, $[\&]$, un elemento clave del bienestar individual y social [y] un recurso favorable para la actividad económica y la generación de empleo. 
Pero que todo el territorio sea paisaje y que el concepto de paisaje tenga un calado patrimonial, no presupone que todos los paisajes sean paisajes patrimoniales. "Patrimonio y patrimonialización implican, hasta ahora, un ejercicio de selección de lo significativo o relevante dentro del amplio universo de bienes patrimonializables"33 y la categoría de paisajes patrimoniales debe circunscribirse a aquellos paisajes que por su carácter merezcan ser objeto de reconocimiento y tutela. El convenio establece, como aspectos básicos a considerar, la protección, gestión y ordenación de los paisajes. Si todos los paisajes deben ser gestionados y una parte debe ser ordenada, aquellos que posean valores singulares requerirán salvaguardia y tutela administrativa ${ }^{34}$. Estos últimos son mayoritariamente los paisajes que merecen el calificativo, aunque el convenio no los denomine así, de paisajes patrimoniales.

A la vista de lo anterior, se suscita la pregunta sobre cómo gestionar la preservación de los paisajes patrimoniales teniendo en cuenta su carácter perceptivo y mutabilidad. La contestación está mediatizada, por una parte, por el propio contenido territorial de los paisajes patrimoniales y, por otra, por los propósitos que justifican las declaraciones

33 Mata, 2012.

34 El Convenio entiende por 'protección de los paisajes' las acciones encaminadas a conservar y mantener los aspectos significativos o característicos de un paisaje, justificados por su valor patrimonial derivado de su configuración natural y/o la acción del hombre (art. 1). patrimoniales. Sobre lo primero, cabe señalar que los paisajes patrimoniales son unidades territoriales complejas, que no se limitan a elementos aislados (castillos, ermitas, conjuntos históricos), a ejes de comunicación (itinerarios culturales), o a expresiones territoriales de actividades económicas (salinas, canteras, minas...). Tales elementos materiales, al igual que otros inmateriales de carácter etnográfico (actividades, creencias...), actúan como vectores de patrimonialización, que son aquellas realidades y/o procesos de interés cultural en torno a los cuales se condensa el carácter patrimonial de un territorio. Estos vectores, pese a su relevancia patrimonial y analítica, no constituyen en sí mismos paisajes patrimoniales. Un paisaje patrimonial se asocia siempre con un territorio cuyo argumento interpretativo deriva de la interacción de sus vectores patrimoniales (materiales e inmateriales), tanto entre sí, como con el resto de la estructura territorial. La relación entre territorio, patrimonio y paisaje constituye, pues, una trilogía fundamental con la que reorientar la identificación, protección y gestión de los bienes culturales.

Respecto a la evolución de los propósitos y justificación de los reconocimientos institucionales, 
llama la atención la evolución desde una intención preferentemente estética y conservacionista, al protagonismo del desarrollo territorial. Ello supone un reforzamiento de las facetas económicas y sociales de los paisajes, entendidos éstos como marcos vitales, espacios para el disfrute ciudadano y activos para el desarrollo. Sin embargo, desde la perspectiva de la gestión se plantea el problema de cómo proteger unidades territoriales complejas y funcionales como los paisajes patrimoniales en los distintos y variados procesos de desarrollo.

\section{La Lista: un instrumento útil pero algo obsoleto}

\section{ASPECTOS GENERALES}

La Lista es un registro patrimonial bien conocido, por lo que en este apartado sólo se señalarán aquellas cuestiones relevantes para los objetivos del artículo. Desde la última reunión del Comité (2013), el número de bienes inscritos asciende a 981 (tabla 1) distribuidos en 130 estados-parte de los 160 adheridos a la Convención -requisito básico para convertirse en estado-parte-. Resta, pues,

190 revista invi № 85 / Noviembre 2015 / Volumen № 30: 181-214 casi un 16\% sin bienes, aunque con importantes diferencias: mientras que en la región Europa y Norteamérica sólo Mónaco no dispone de ninguno; en los Estados Árabes son dos; seis en América Latina y El Caribe; diez en África y otros diez en Asia-Pacífico.

El objetivo básico de la Convención es la corresponsabilidad internacional en la preservación de bienes patrimoniales con valor excepcional universal (ver más adelante). La competencia para proponer nuevos bienes a la Lista corresponde a los estados-parte, que previamente han debido elaborar listas indicativas; éstas son elencos de bienes merecedores, siempre según estos estados-parte-, de integrar la Lista. Habitualmente son bienes sobre cuya candidatura ya se está trabajando y que se pretende elevar al Comité para su consideración en años venideros ${ }^{35}$.

La inscripción de bienes en la Lista se liga al mencionado valor universal excepcional, entendiendo como tal la combinación de valores patrimoniales que se dan en un bien y cuyo carácter singular o, al contrario, representativo, le permiten cumplir con alguno de los diez criterios establecidos por el Comité; con éstos se fundamenta su incorporación a la Lista y se determina el tipo de bien (seis criterios

35 Las listas indicativas vienen funcionando de forma poco homogénea entre los distintos estados-parte. Algunos de los bienes inscritos en ellas terminan entrando en una especie de limbo cuando, transcurridos más de siete u ocho años, los estadosparte no se deciden a presentarlos oficialmente.

ARTíCULO: Los paisajes culturales de Unesco desde la perpectiva de AméricaLatina y el Caribe. Conceptuaciones, situciones y potencialidad / Rocio Silva Pérez, Victor 
TABLA 1. DISTRIBUCIÓN Y TIPOLOGÍA DE LOS BIENES INSCRITOS EN LA LISTA (2013)

\begin{tabular}{l|c|c|c|c|c}
\hline REGIÓN UNESCO & CULTURAL & NATURAL & MIXTO & TOTAL & $\%$ \\
\hline África & 48 & 36 & 4 & 88 & $9 \%$ \\
\hline Estados Árabes & 68 & 4 & 2 & 74 & $8 \%$ \\
\hline Asia y Pacífico & 154 & 57 & 10 & 221 & $23 \%$ \\
\hline Europa y Norteamérica & 399 & 60 & 10 & 469 & $48 \%$ \\
\hline Latinoamérica y Caribe* & 90 & 36 & 3 & 129 & $13 \%$ \\
\hline Total & 759 & 193 & 29 & 981 & $100 \%$ \\
\hline Porcentaje & $78 \%$ & $19 \%$ & $3 \%$ & $100 \%$ & \\
\hline
\end{tabular}

* Unesco identifica 129 bienes de la Lista en esta región porque no considera en ella a Puerto Rico ni Curaçao. En este trabajo, al partir del territorio como referencia, sí se han contabilizado; de forma que el total asciende a 131 (ver tabla 5).

Fuente: Unesco, 2013a, elaboración propia

culturales y cuatro naturales; si se combina al menos un criterio natural y otro cultural, se habla de bien mixto; véase la tabla 4 para conocer los criterios). Los criterios por los que se han inscrito cada uno de los bienes de la Lista ofrecen, ya de por sí, unas primeras claves para su preservación y gestión. Además, el bien debe acreditar un elevado grado de autenticidad y de integridad.

Casi desde el inicio de la Lista, surgen procesos inesperados que influirán notablemente en su

ARTíCULO: Los paisajes culturales de Unesco desde la perpectiva de AméricaLatina y el Caribe. Conceptuaciones, situciones y potencialidad / Rocio Silva Pérez, Victor Fernández Salinas desarrollo. Recuérdese que su andadura empieza a finales de los años setenta, cuando el planeta, como en la actualidad, se encontraba inmerso en un importante proceso de reestructuración socioeconómica. Otros procesos influyentes son: la gran expansión del turismo cultural; la necesidad de mejorar la imagen de ciudades y territorios; $y$, no menos importante, la progresiva complejidad conceptual del patrimonio, que engloba nuevas categorías y da valor a expresiones culturales cuyo aprecio apenas despuntaba en los años setenta. 
Unesco, a través del Comité, ha encarado estos procesos con diversas medidas; unas han pasado por la revisión conceptual y otras se han relacionado con nuevas fórmulas de protección y gestión de los bienes. De hecho, la Lista, revisada anualmente en cada Comité, alienta indirectamente un continuo debate científico y técnico sobre el reconocimiento y tutela patrimonial. Sin embargo, su desarrollo ha dado lugar a no pocos problemas (tabla 2). Los más importantes, en cuanto que significan una revisión de fondo de la política del Comité, son los conceptuales. Ante la dificultad que supondría efectuar cambios en el texto de la Convención, que obligaría a una revalidación general de los estados-parte, estos problemas se han subsanado con la inclusión de nuevos parágrafos en las sucesivas publicaciones de las Directrices. Las primeras (30 parágrafos) se adoptan en 1978 al inaugurar la Lista; desde entonces se han revisado más de una decena veces, la última significativa en 2005 (290 parágrafos), aunque ha habido publicaciones posteriores. Este método ha actualizado conceptualmente la Lista, pero sin una visión global, coherente y sistemática del patrimonio.

\section{TABLA 2. PROBLEMAS Y MEDIDAS DEL COMITÉ ANTE EL DESARROLLO DE LA LISTA}

\begin{tabular}{l|l}
\hline Problemas & Medidas \\
$\begin{array}{l}\text { Conceptuales } \\
\begin{array}{l}\text { Vicisitudes sobrevenidas respecto a la protección de los valo- } \\
\text { res del bien }\end{array}\end{array}$ & $\begin{array}{l}\text { Inclusión de conceptos nuevos o reelaborados en las } \\
\text { Directrices }\end{array}$ \\
\hline $\begin{array}{l}\text { y Lista del Patrimonio en Peligro } \\
\text { Crecimiento acelerado de la Lista y desequilibrios entre los } \\
\text { tipos de bienes }\end{array}$ & $\begin{array}{l}\text { Estrategia global para la consecución de una Lista del Patrimo- } \\
\text { nio Mundial representativa, equilibrada y creíble }\end{array}$ \\
\hline $\begin{array}{l}\text { Seguimiento } \\
\text { Presión política sobre las decisiones del Comité frente a los } \\
\text { informe técnicos de las entidades asesoras (Icomos/Uicn) }\end{array}$ & $\begin{array}{l}\text { Informes periódicos regionales de los estados-parte sobre la } \\
\text { situación de sus bienes }\end{array}$ \\
\hline $\begin{array}{l}\text { Retos relacionados con la gestión de unos bienes cada vez más } \\
\text { diferentes y complejos }\end{array}$ & Orientaciones sin corpus consolidado en las Directrices \\
\hline
\end{tabular}

Fuente: Elaboración propia 
Otros problemas han sido los acaecidos a los bienes de la Lista tras su inclusión, que en muchos casos se han generado a causa de una gestión inadecuada de los bienes inscritos. La mayor parte de los problemas se han manejado a partir de los informes sobre el estado de conservación (soc), realizados por miembros de las entidades asesoras y por técnicos designados por el Centro del Patrimonio Mundial, que es el secretariado del Comité. Estos soc fueron poco relevantes hasta los años noventa (nunca sobrepasaban los 20 por año); pero en los noventa acusaron un notable incremento (109 en 1998) y se hacen muy numerosos en el nuevo siglo, hasta el punto de que su discusión ocupa una parte importante de la duración de los comités (178 en 2009; 169 en 2013). A partir de estos soc, el Comité valora los problemas que los motivaron e insta a los estados-parte a solventarlos.

Caso de no llegar a una solución a través de esta vía, el paso siguiente es la inclusión en la Lista del Patrimonio en Peligro (tabla 3), que es un registro ya previsto en la Convención donde se inscriben aquellos bienes sometidos a impactos, presiones, procesos o propuestas que alteran o pueden alterar sus valores. Pero el Comité ha sido cauto en la inclusión de bienes en ella, salvo en casos de alarma extrema, a causa de la renuencia de los estadosparte afectados. En la Lista del Patrimonio en Peligro, la representación regional es bien distinta a la que se observa en la Lista general: los países africanos y los estados árabes representan el 63\% de los registros, frente a una participación global en la Lista de sólo el 17\%; América Latina y El Caribe tiene un $16 \%$ de bienes en Peligro cuando su representación es del 13\%. También hay que destacar el elevado porcentaje de bienes naturales (41\%), sobre todo si se compara con su presencia global en la Lista (19\%). Las decisiones del Comité sobre los bienes en la Lista del Patrimonio en Peligro son más coercitivas y, o bien se resuelven en un período corto de tiempo (en torno a dos o tres años), o se convierten en bienes que podrían denominarse estables en ese registro (caso de la ciudad vieja de Jerusalén -desde 1982- o de la zona arqueológica de Chan Chan en Perú - desde 1986, el mismo año de su inscripción-. La expulsión de la Lista ha sido hasta el momento un hecho excepcional. 
TABLA 3. DISTRIBUCIÓN Y CARÁCTER DE LOS BIENES INSCRITOS EN LA LISTA DEL PATRIMONIO EN PELIGRO (2013)

\begin{tabular}{|c|c|c|c|c|c|}
\hline Región Unesco & Culturales & Naturales & Mixtos & Total & $\%$ \\
\hline África & 4 & 12 & 0 & 16 & $36 \%$ \\
\hline Estados Árabes & 12 & 0 & 0 & 12 & $27 \%$ \\
\hline Asia y Pacífico & 3 & 1 & 0 & 4 & $9 \%$ \\
\hline Europa y Norteamérica & 4 & 1 & 0 & 5 & $11 \%$ \\
\hline Latinoamérica y Caribe & 4 & 3 & 0 & 7 & $16 \%$ \\
\hline Total & 26 & 18 & 0 & 44 & $100 \%$ \\
\hline$\%$ & $59 \%$ & $41 \%$ & $0 \%$ & $100 \%$ & \\
\hline
\end{tabular}

Fuente: Unesco, 2013a, elaboración propia

Respecto al fuerte incremento de bienes en la Lista y los desequilibrios que esto ha provocado (tanto entre los bienes culturales y naturales, como entre las distintas regiones del planeta), en 1994 se realiza una reunión de expertos que genera la llamada Estrategia global para la consecución de una Lista del Patrimonio Mundial representativa, equilibrada y creíble (incorporada a las Directrices en los parágrafos 55 al 58). En ella se llama la atención sobre la sobrerepresentación de los siguientes tipos de bienes: a) europeos; b) ciudades históricas y edificios religiosos; c) relacionados con el cristianismo; d) de "períodos históricos frente a la Prehistoria y al siglo XX"; y e) de arquitectura noble y monumental frente a la vernácula. En general, se critica la escasa presencia de la mayor parte de las culturas vivas y tradicionales, con su profundidad, riqueza, complejidad y forma de relacionarse con su medio; la primacía de los valores arquitectónicos, frente a otras dimensiones patrimoniales: naturales, socioeconómicas, simbólicas y filosóficas; y la división simplista entre bienes culturales 
y naturales, cuya única expresión interactiva es la de los bienes mixtos.

A partir de esta Estrategia, se generan prioridades que se consolidan con la Declaración de Budapest sobre el Patrimonio Mundial de 2002, justo en el momento en el que se exacerban los problemas de crecimiento de la Lista. Estas prioridades, entre otras medidas, limitan a dos las inscripciones anuales por estado-parte (sólo una puede ser cultural), y dan preferencia en las nuevas inscripciones a bienes: de países sin presencia en la Lista; de países con tres bienes o menos; naturales o de carácter mixto; transnacionales; de África, Pacífico y Caribe; de países que hayan ratificado la convención en los últimos diez años; de países que no han presentado propuestas desde hace más de diez años...

Además, Unesco incorpora nuevos métodos con que valorar las candidaturas: se afina en la determinación del valor universal excepcional; se da máxima importancia a la existencia y calidad de planes de gestión para los bienes (los estados-parte que envíen candidaturas a Unesco deben acreditar, no sólo el valor de estos, sino que existen estrategias y recursos para conservarlos, pero no se abunda en los argumentos básicos y sustentadores de la gestión de los distintos tipos de bienes de la Lista); y se limita a 45 el máximo de candidaturas que el Comité estudia cada año.
Otro aspecto relevante es el seguimiento de los bienes. El Comité ha considerado que los soc no pueden ser la única vía de conocer los avatares que afectan a los bienes, dado que éstos sólo se realizan prioritariamente cuando ya existen problemas. Surgen así los llamados informes periódicos, elaborados por los estados-parte sobre el grado de adecuación a la Convención de sus bienes y su estado de conservación. Se ejecutan sexenalmente y por regiones; los primeros fueron realizados por los estados árabes en 2000. La crítica a estos informes es que son elaborados por los estados-parte y no por los organismos asesores independientes de Unesco, por lo que sus resultados siempre atenúan los problemas que afectan a los bienes y hacen énfasis en los aspectos positivos de su gestión.

Por último, cabe señalar una cuestión a la que el Comité no se ha enfrentado explícitamente: la incidencia de las influencias políticas en sus decisiones, ya que en ocasiones éstas están lejos de las propuestas de los informes técnicos de los organismos asesores a causa de las presiones que los estados-parte efectúan para evitar decisiones críticas. Esto ha dado pie a que se hable de comités blandos y de comités duros (según el rigor con que se ha aplicado la filosofía de la Convención y las Directrices en el año en que se han celebrado) y, en general, contribuye a restar credibilidad al Comité en la gestión de sus responsabilidades. 


\section{Los paisajes culturales de Unesco y su consideración en la Lista}

\section{ASPECTOS GENERALES}

El debate sobre los paisajes culturales en Unesco tampoco está exento de dificultades, ya que dicha figura se superpone de forma un tanto forzada a las categorías de bienes culturales, naturales y mixtos, las dos primeras con tres subcategorías cada una. De ello se deriva una cierta confusión, no atajada por Unesco, que se evidencia en el propio portal del Centro del Patrimonio Mundial, en el que se ofrecen dos listados no coincidentes de paisajes culturales (uno con 93 registros y otro con 83) ${ }^{36}$. El número de paisajes culturales, contabilizando los incluidos en los dos listados, asciende a 115, casi el 12\% de los bienes de la Lista.

También puede calificarse de simplista la clasificación de los paisajes culturales en los tres tipos manejados por Unesco: a) paisajes definidos, diseñados y creados por el hombre, como parques y jardines; b) paisajes evolutivos, que a su vez se diferencian entre: fósiles y continuos en el tiempo; y c) los paisajes asociativos, que están relacionados con creencias, obras artísticas o creaciones culturales.

Ver Unesco, 2013a; Unesco, s.f.

196 revista invi № 85 / Noviembre 2015 / Volumen № 30: 181-214
Se trata de categorías meramente conceptuales ${ }^{37}$ y poco eficaces para un reconocimiento ajustado de los numerosos e indisociables valores patrimoniales que poseen los paisajes. Por otra parte, todo en el paisaje es dinámico; e incluso aquellos con escasos cambios formales u objetivables están sometidos a los cambios a los que inducen las percepciones. Si se acepta que el paisaje es percepción, la categoría paisajes fósiles resulta poco apropiada, puesto que estos también evolucionan, si no en su realidad física, sí en las miradas que suscitan. Pero aunque simplistas y a veces poco eficaces, son categorías que resultan operativas en la búsqueda de instrumentos de gestión.

Otro aspecto a considerar en la conceptualización y posibilidades de gestión de los paisajes culturales es su extensión. A este respecto, hay que tener en cuenta que, como sucede al resto de los bienes, Unesco exige una delimitación espacial precisa del bien, la llamada área clasificada (nominated site) y de su zona de amortiguamiento (buffer zone). Respecto a los paisajes culturales, el total de hectáreas que ocupan aquellos que ofrecen datos sobre su superficie en el portal del Centro del Patrimonio Mundial (108 de los 115 señalados) asciende a 42.083 .474 ha en las áreas clasificadas y 3.566.243 en las zonas de amortiguamiento. Las diferencias entre los mayores (Papahãnaumokuãkea -Estados Unidos-, 36.207.499 ha) y los menores

37 Fowler, 2003. 
(Sitio de Palmera-Siria-, 0,36 ha) habla por sí sola de la falta de un criterio certero en la determinación de qué son y cómo se proyectan en el territorio los paisajes culturales.

El número de paisajes culturales inscritos desde 1993 evidencia una tendencia al alza, si bien no continua ni regular. Con relación a los criterios más frecuentemente utilizados en sus declaraciones, éstos son el v, el iv (este criterio y el ii son los únicos que mencionan el paisaje explícitamente, tabla 4) y, sobre todo, el iii; más de la mitad de los paisajes de la Lista cumplen éste $(63,0 \%)$ y el iv $(59,3 \%)$ y, en consecuencia, se puede afirmar que para el Comité, en la praxis, un paisaje cultural es aquel que aporta un testimonio único o al menos excepcional de una tradición cultural de una civilización existente y desaparecida. Los criterios naturales, como pudiera parecer previsible, que no lo justificable, son los menos considerados; sólo el vii aparece en un número significativo de paisajes $(9,9 \%)$ y lo hace fundamentalmente por cuestiones de carácter estético.

Por último, está la cuestión de los citados bienes mixtos, de los que hay 29 en la Lista. Si bien todos tienen un marcado valor paisajístico cultural, sólo 12 están reconocidos explícitamente como paisajes culturales.

\section{Una mirada desde América Latina y El Caribe a los paisajes culturales de Unesco}

\section{AMÉRICA LATINA Y EL CARIBE EN LA LISTA DEL PATRIMONIO MUNDIAL}

Con 131 bienes inscritos en la Lista, esta región posee el 13\% los bienes registrados en ella. De su distribución (figura 1) se colige una mayor densidad en los espacios más poblados históricamente, con un marcado carácter urbano y en los que hay una mayor concentración de actividades económicas. Frente a ellos, los espacios rurales de economías más deprimidas y con una mayor significación de los colectivos indígenas están relativamente menos representados. Además, pese a la impresión de difusión que ofrece el mapa, hay una importante concentración en no demasiados países. Entre Argentina, México y Perú casi alcanzan la mitad de los bienes $(46,56 \%)$ y sólo México posee uno de cada cuatro $(24,42 \%)$.

revista invi № 85 / Noviembre2015 / Volumen №30: 181-214 197 
TABLA 4. FRECUENCIA DE LOS CRITERIOS RECONOCIDOS EN LAS DECLARACIONES DE PAISAJES CULTURALES DE LA LISTA

\begin{tabular}{|c|c|c|}
\hline \multicolumn{2}{|c|}{ Criterios } & Frecuencia \\
\hline \multirow{6}{*}{ 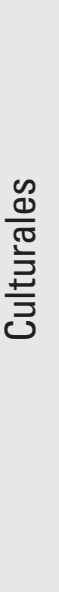 } & i. Representar una obra maestra del genio creativo humano. & 16 \\
\hline & $\begin{array}{l}\text { ii. Atestiguar un intercambio de valores humanos considerable, durante un período concreto o en un área } \\
\text { cultural del mundo determinada, en los ámbitos de la arquitectura o la tecnología, las artes monumentales, } \\
\text { la planificación urbana o la creación de paisajes. }\end{array}$ & 43 \\
\hline & $\begin{array}{l}\text { iii. Aportar un testimonio único, o al menos excepcional, sobre una tradición cultural o una civilización viva o } \\
\text { desaparecida. }\end{array}$ & 72 \\
\hline & $\begin{array}{l}\text { iv. Ofrecer un ejemplo eminente de un tipo de edificio, conjunto arquitectónico o tecnológico o paisaje, que } \\
\text { ilustre una etapa significativa de la historia humana. }\end{array}$ & 66 \\
\hline & $\begin{array}{l}\text { v. Ser un ejemplo destacado de formas tradicionales de asentamiento humano o de utilización de la tierra } \\
\text { o del mar, representativas de una cultura (o de varias culturas), o de interacción del hombre con el medio, } \\
\text { sobre todo cuando éste se ha vuelto vulnerable debido al impacto provocado por cambios irreversibles. }\end{array}$ & 45 \\
\hline & $\begin{array}{l}\text { vi. Estar directa o materialmente asociado con acontecimientos o tradiciones vivas, ideas, creencias u obras } \\
\text { artísticas y literarias que tengan una importancia universal excepcional. }\end{array}$ & 41 \\
\hline \multirow{4}{*}{ 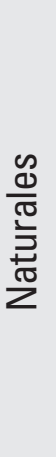 } & vii. Representar fenómenos naturales o áreas de belleza natural e importancia estética excepcionales. & 11 \\
\hline & $\begin{array}{l}\text { viii. Ser ejemplos eminentemente representativos de las grandes fases de la historia de la tierra, incluido el } \\
\text { testimonio de la vida, de procesos geológicos en curso en la evolución de las formas terrestres o de elemen- } \\
\text { tos geomórficos o fisiográficos significativos. }\end{array}$ & 3 \\
\hline & $\begin{array}{l}\text { ix. Ser ejemplos eminentemente representativos de procesos ecológicos y biológicos en curso en la evolu- } \\
\text { ción y el desarrollo de los ecosistemas terrestres, acuáticos, costeros y marinos y las comunidades de vege- } \\
\text { tales y animales terrestres, acuáticos, costeros y marinos. }\end{array}$ & 5 \\
\hline & $\begin{array}{l}\text { x. Contener los hábitats naturales más representativos y más importantes para la conservación in situ de } \\
\text { la diversidad biológica, comprendidos aquellos en los que sobreviven especies amenazadas que tienen un } \\
\text { valor universal excepcional desde el punto de vista de la ciencia o de la conservación. }\end{array}$ & 8 \\
\hline
\end{tabular}

Fuente: Unesco, 2013a, elaboración propia 
FIGURA 1: DISTRIBUCIÓN DE LOS BIENES DE AMÉRICA LATINA Y CARIBE EN LA LISTA

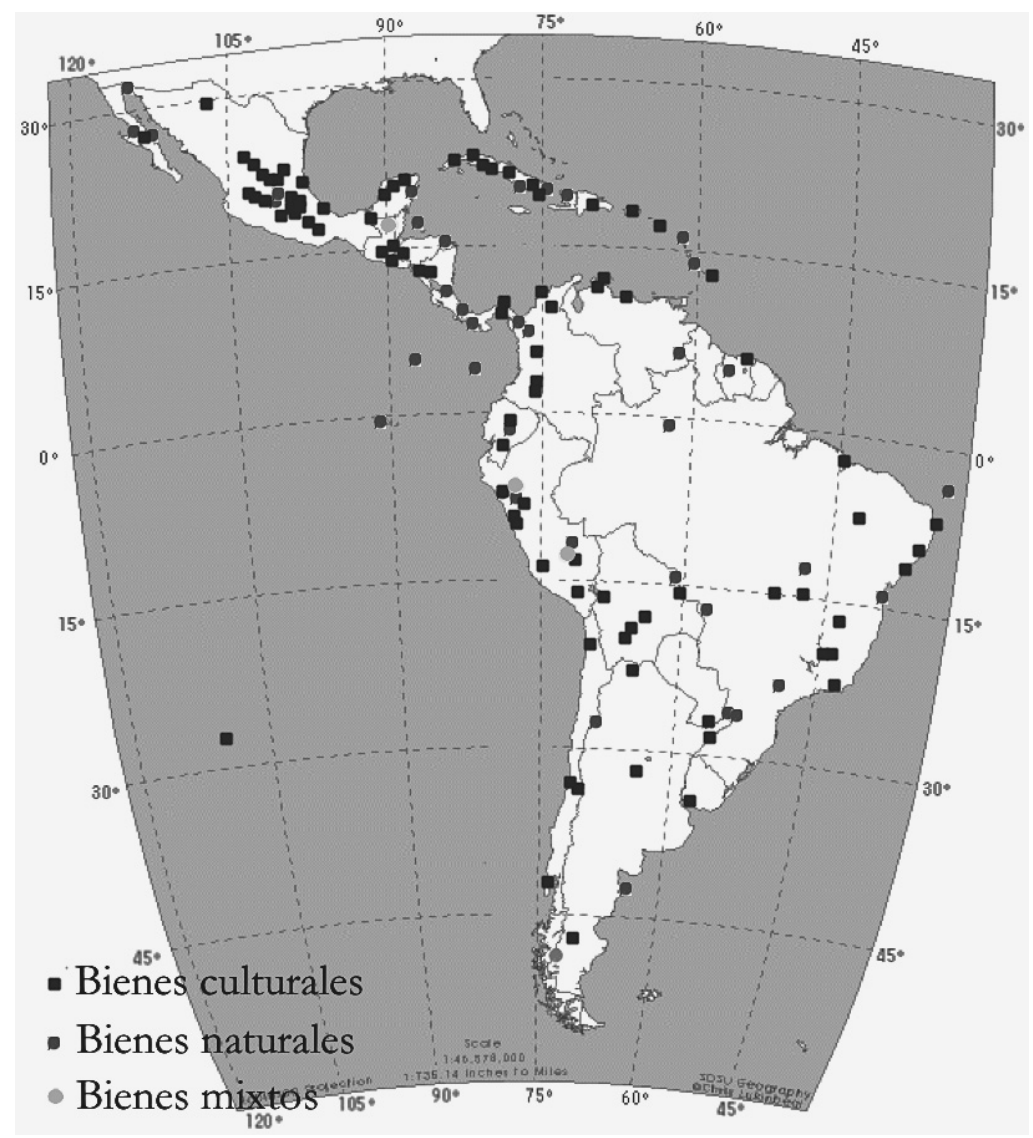

Fuente: Unesco, 2013a, elaboración propia 


\section{RESPECTO AL CARÁCTER INSTITUCIONAL DE LOS TERRITORIOS DE ESTA REGIÓN, UNESCO IDENTIFICA:}

a Estados-parte. De los 33 países de la región, todos salvo Bahamas se han adherido a la Convención.

b Miembros asociados. Son territorios con altos niveles de autonomía, si bien todavía pertenecen a una metrópoli colonial. Los seis de esta región son caribeños; Aruba, Curaçao y Saint Marteen (Países Bajos) y Anguila, Islas Caimán e Islas Vírgenes (Reino Unido).

c Otros territorios pertenecientes a metrópolis extranjeras, pero sin el carácter de miembro asociado: Bonaire, Saint Eustatius y Saba (Países Bajos); e Islas Turks y Caicos (Reino Unido).

d Casos aparte son Puerto Rico, con autogobierno y estatuto de Estado libre asociado de Estados Unidos, pero que para Unesco es un territorio más de este país; y la Isla de Pascua, adscrita a Chile, aunque geográficamente esté en la región Pacífico.

En cuanto a la proporción entre bienes culturales (91), naturales (37) y mixtos (3), en América Latina y El Caribe se aprecia una considerable desproporción entre unos y otros, si bien con datos menos contrastados que los comentados para el conjunto de la Lista. Hay, además, siete bienes incluidos en la Lista del Patrimonio en Peligro ${ }^{38}$, que suponen algo más del 5\% de los bienes de la región.

\section{Perspectivas de América Latina y el Caribe en relación con las estrategias del Comité para la gestión de la Lista}

Dado su peso específico en la Lista, América Latina y El Caribe posee todavía capacidad para crecer con menos cortapisas que otras regiones. Sin embargo, las propuestas tendrán más oportunidades de ser aceptadas si, además de un valor universal excepcional incuestionable y un sistema de gestión adecuado, cumplen adicionalmente los requisitos ya señalados al presentar la Estrategia global para la consecución de una Lista del Patrimonio Mundial representativa, equilibrada y creíble (tabla 5).

38 Red de reservas del arrecife de barrera en Belice (Belice); Oficinas salitreras de Humberstone y Santa Laura (Chile); Parque Nacional Los Katíos (Colombia); Reserva de la Biosfera Río Platano (Honduras); Fortificaciones de la costa caribeña de Panamá: Portobelo y San Lorenzo (Panamá); Zona arqueológica de Chan Chan (Perú) y Coro y su puerto (Venezuela). 
TABLA 5. SITUACIÓN DE LOS PAÍSES Y TERRITORIOS DE AMÉRICA LATINA Y EL CARIBE SEGÚN LAS PRIORIDADES DEL COMITÉ DEL PATRIMONIO MUNDIAL

\begin{tabular}{|c|c|c|c|c|c|c|c|}
\hline Países y territorios & $\begin{array}{l}\text { Sin bienes en la } \\
\text { Lista del } \\
\text { Patrimonjo } \\
\text { Munncial }\end{array}$ & $\begin{array}{l}\text { Con } 3 \text { bienes } \\
\text { o menos }\end{array}$ & Del Caribe & $\begin{array}{l}\text { Con ratificación de } \\
\quad \text { la convención } \\
\text { en últirmos } 10 \text { años }\end{array}$ & $\begin{array}{c}\text { Sin propuestas en } \\
10 \text { años }\end{array}$ & $\begin{array}{c}\text { Con lista indicativa } \\
\text { actualizada } \\
\left(\mathrm{n}^{\circ} \text { de bienes }\right. \\
\text { en ella) }\end{array}$ & $\begin{array}{l}\text { Posibilidades en } \\
\text { razón de las } \\
\text { columnas } \\
\text { anteriores }\end{array}$ \\
\hline $\begin{array}{l}\text { Anguila (estado asociado de Unesco, depende } \\
\text { de Reino Unido ) }\end{array}$ & & & & & & & $* * * * *$ \\
\hline Antigua y Barbuda & & & & & & 1 & $* * * * *$ \\
\hline Argentina & & & & & & 6 & * \\
\hline $\begin{array}{l}\text { Aruba (estado asociado de Unesco, depende de } \\
\text { Paises Bajos) }\end{array}$ & & & & & & & $* * * *$ \\
\hline \multicolumn{8}{|l|}{ Bahamas } \\
\hline Barbados & & & & & & 2 & $* * *$ \\
\hline Belice & & & & & & & ** \\
\hline Bolivia & & & & & & 6 & $* *$ \\
\hline $\begin{array}{l}\text { Bonaire, San Eustaquio y Saba (municipio } \\
\text { especial de Paises Bajos) }\end{array}$ & & & & & & 2 & $* * * * *$ \\
\hline Brasil & & & & & & 7 & * \\
\hline Chile & & & & & & 18 & * \\
\hline Colombia & & & & & & 19 & * \\
\hline Costa Rica & & & & & & 2 & $* * *$ \\
\hline Cuba & & & & & & 3 & $* *$ \\
\hline $\begin{array}{l}\text { Curaçao (estado asociado de Unesco, depende } \\
\text { de Países Bajos) }\end{array}$ & & & & & & 1 & $* * * *$ \\
\hline Dominica & & & & & & & $* *$ \\
\hline Ecuador & & & & & & 7 & $* *$ \\
\hline El Salvador & & & & & & 6 & $* * *$ \\
\hline Granada & & & & & & 3 & $* * * * *$ \\
\hline Guatemala & & & & & & 21 & $* * *$ \\
\hline Guyana & & & & & & 5 & $* * * *$ \\
\hline
\end{tabular}




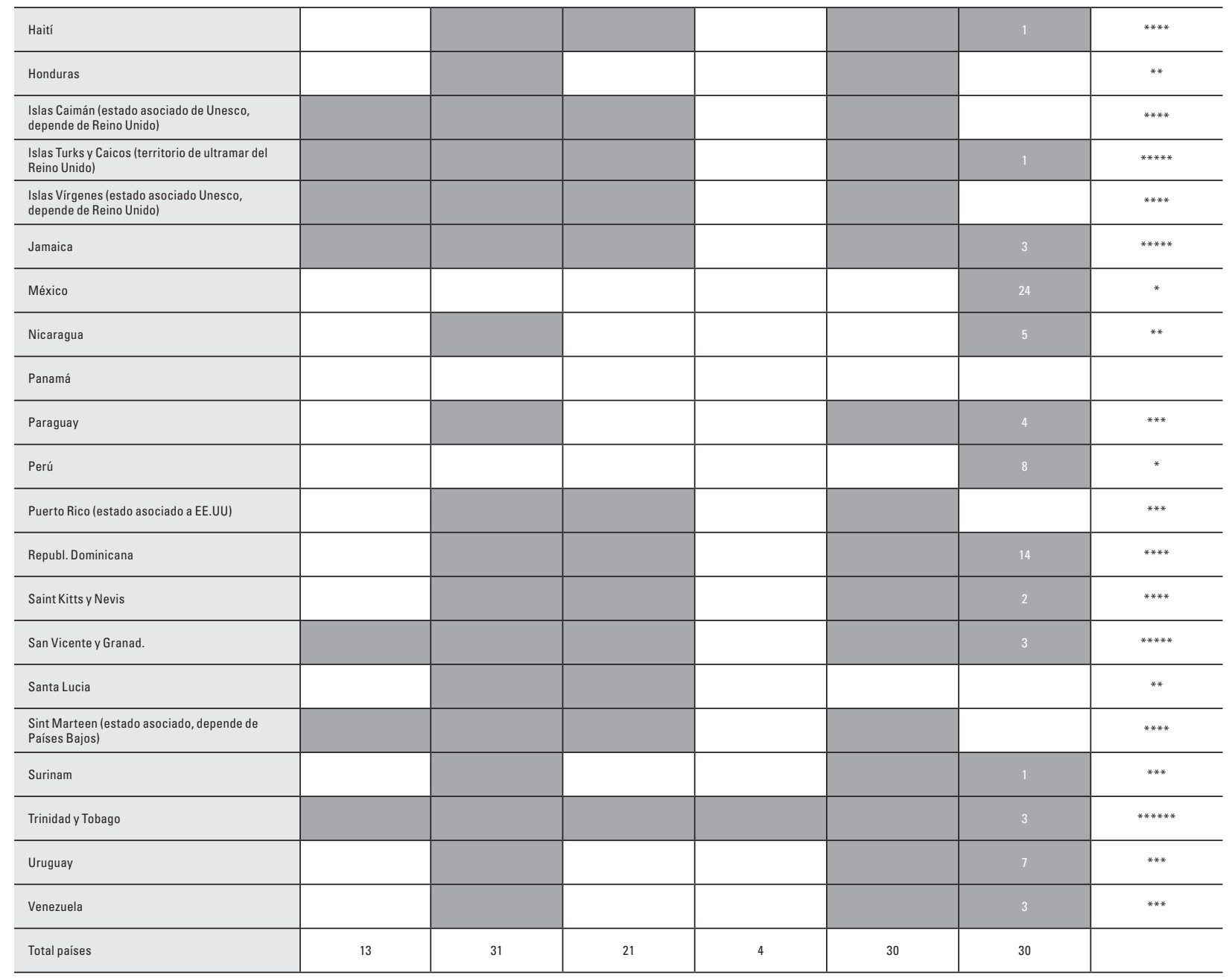

* En sombreado, aquellos países y territorios en cada una de las situaciones.

Fuente: Unesco, 2013a, elaboración propia 
Una vez que un país se convierte en estado-parte tras adherirse a la Convención, requisito que cumplen 32 de los 33 países de la región, el Comité otorga máxima prioridad a aquellos que no tengan bienes en la Lista. De los 42 territorios considerados, hay 13 que están en esta situación. La mayoría son islas caribeñas, a las que se añade Guyana. La segunda prioridad se relaciona con los que poseen 3 o menos bienes, situación en la que se encuentra la mayoría de los territorios: 31 . La tercera prioridad se centra precisamente en reforzar la presencia del Caribe; con lo que sus 21 territorios tienen una considerable ventaja.

De la tabla 5 también se infiere una escasa voluntad o capacidad de la región para aumentar su presencia en la Lista: 32 de los 33 territorios no han incorporado ningún bien durante los diez últimos años; sin embargo, esto se convierte en una ventaja al coincidir con otra prioridad. En cambio, se ha mostrado mayor diligencia en crear listas indicativas (con un total de 188 propuestas), pues la mayoría de los territorios (30) tiene bienes en alguna de ellas. En todo caso, los miembros asociados y los otros territorios son los menos considerados: sólo Bonaire, Sint Estatius y Saba (Países Bajos) y las Islas Turks y Caicos (Reino Unido) tienen bienes en las listas indicativas de los países a los que pertenecen políticamente. México, Guatemala, Colombia y Chile son los países con listas más extensas: suman el $43 \%$ de los bienes en el total de listas indicativas de la región.
Menos relevante es el cumplimiento de la prioridad referida a los estados-parte adheridos a la Convención durante los últimos diez años, requisito que sólo cumple Trinidad y Tobago, sin lugar a dudas el estado-parte del conjunto planeta, y no sólo de esta región, que mejor se adapta a las prioridades del Comité.

A lo anterior debe añadirse la ventaja que adquiriría cualquier propuesta que fuese transnacional; de carácter natural o mixto; que se encuadrase en tipologías poco o medianamente representadas (entre ellas los paisajes culturales); o cuyo valor excepcional universal, caso de tratarse de un bien cultural o mixto, se sustente en los criterios menos frecuentes (i, ii y vi).

\section{LOS PAISAJES CULTURALES Y LOS BIENES MIXTOS DE AMÉRICA LATINA Y EL CARIBE}

Se pueden identificar 9 paisajes culturales en América Latina y El Caribe (ver tabla 6 y figura 2). Ninguno de ellos, pese a la potencia de sus valores físicos, ha sido incluido observando algún criterio natural. Todos son de carácter evolutivo; es decir, no hay paisajes relacionados con jardines o paisajes construidos; ni tampoco hay paisajes asociativos, aunque muchos proyecten una importante connotación asociada a procesos históricos, símbolos o creencias. Sí puede diferenciarse entre los evolutivos fósiles y los evolutivos continuos, existiendo una cierto equilibrio entre ellos inclinado ligeramente hacia los continuos. 
TABLA 6: PAISAJES CULTURALES DE AMÉRICA LATINA Y EL CARIBE

\begin{tabular}{|c|c|c|c|c|c|c|c|c|c|c|c|c|c|c|c|c|}
\hline \multirow{2}{*}{ Paisaje } & \multirow{2}{*}{ Tipo } & \multicolumn{2}{|c|}{ Listado } & \multirow{2}{*}{$\begin{array}{l}\text { Inscrip- } \\
\text { ción }\end{array}$} & \multicolumn{10}{|c|}{ Criterios } & \multicolumn{2}{|c|}{ Extensión (ha) } \\
\hline & & A & B & & . & $:=$ & $: \equiv$ & $\geq$ & $>$ & $>$ & $: \overline{>}$ & $: \overline{5}$ &.$\underline{x}$ & $\times$ & $\begin{array}{c}\text { Área } \\
\text { clasificada }\end{array}$ & $\begin{array}{c}\text { Área } \\
\text { amorti-guam. }\end{array}$ \\
\hline Quebrada de Humahuaca (Argenti.) & Evol. fós. & $x$ & $x$ & 2003 & & & & & & & & & & & 171.116 & 369.649 \\
\hline Rio de Janeiro (Brasil) & Evol. co. & $x$ & $x$ & 2012 & & & & & & & & & & & 7.249 & 8.621 \\
\hline Cafetales de Colombia (Colombia) & Evol. co. & $x$ & $x$ & 2011 & & & & & & & & & & & 141.120 & 207.000 \\
\hline Valle de Viñales (Cuba) & Evol. co. & $x$ & $\mathrm{x}$ & 1999 & & & & & & & & & & & 13.200 & - \\
\hline Paisaj. arqueol. prim. café (Cuba) & Evol. fós. & & $x$ & 2000 & & & & & & & & & & & 81.475 & - \\
\hline Agaves e inst. de tequila (México) & Evol.co. & $x$ & $x$ & 2006 & & & & & & & & & & & 35.019 & 51.261 \\
\hline Cuevas de Yagul y Mitla (México) & Evol. fós. & $x$ & $x$ & 2010 & & & & & & & & & & & 1.515 & 3.860 \\
\hline Totales & & 8 & 7 & & 2 & 3 & 3 & 5 & 5 & 4 & & & & & 459.528 & 640.391 \\
\hline
\end{tabular}

* En sombreado, los criterios por los que se han reconocido los paísajes culturales de América latina y El Caribe.

Fuente: Unesco, 2013a, elaboración propia

De lo anterior se colige cierta importancia en la región de paisajes vinculados a culturas vivas y tradicionales, precisamente aquellas menos representadas en el conjunto de paisajes culturales del planeta según el diagnóstico de la Estrategia Global de 1994. Se trata, por otra parte, de paisajes particularmente complejos, muy diferentes entre sí en cuanto a estructuras socioeconómicas y formas de relacionarse con el medio. Se incluyen en este grupo paisajes de raigambre agraria (plantaciones de tabaco del Valle de Viñales, cultivo del ágave en

204 revista invi № 85 / Noviembre 2015 / Volumen № 30: 181-214
Jalisco, triángulo cafetero de Colombia); urbanos (Río de Janeiro); mineros (Guanajuato), con distintos interlocutores sociales y diferentes necesidades e instrumentos de gestión. Muy distinta es la situación de los paisajes culturales fósiles (Quebrada de Humahuaca, Parque Nacional Rapa Nui, Cuevas de Yagul y Mitla), en los que su puesta en valor se relaciona con la potenciación de las actividades turísticas, lo que igualmente debería repercutir en pro del desarrollo de las comunidades locales. Desde esta perspectiva, el diagnóstico socioeconómico

ARTÍCULO: Los paisajes culturales de Unesco desde la perpectiva de AméricaLatina y el Caribe. Conceptuaciones, situciones y potencialidad / Rocio Silva Pérez, Victor 


\section{FIGURA 2: PAISAJES CULTURALES Y BIENES MIXTOS DE AMÉRICA LATINA Y EL CARIBE}

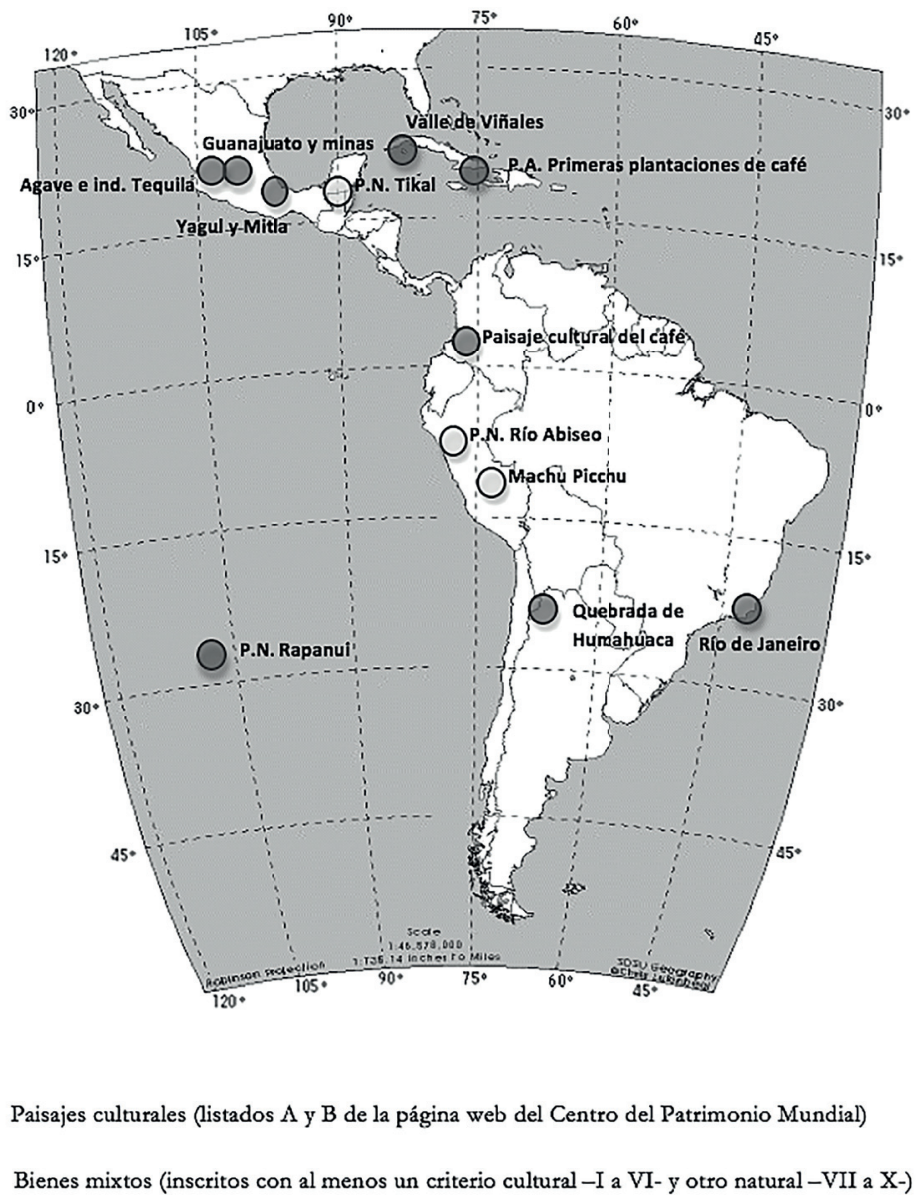

Fuente: Unesco 2013a, elaboración propia 
de los paisajes culturales de América Latina y El Caribe podría ofrecer algunas pistas para avanzar en el complejo debate sobre los instrumentos y posibilidades de gestión de los paisajes culturales.

Se trata, por otra parte, de un conjunto muy dispar de paisajes en lo que respecta a los criterios utilizados para su inscripción. Los más frecuentes son el iv y el v, y el menos el i; o sea, la mayoría se trata de paisajes ilustrativos de las etapas significativas de la historia humana y/o ejemplos eminentes de formas de asentamiento y de utilización del territorio. Tales criterios condensan los valores reconocidos a estos paisajes, erigiéndose en otros tantos condicionantes de cara a la gestión, que en este caso debería estar orientada a la preservación de tales valores.
En cuanto a sus superficies, si bien las diferencias no son tan marcadas como las presentadas para el conjunto mundial, existe una gran diversidad de extensiones que requerirían una gestión diferenciada: frente a las 1.514 ha de Cuevas de Yagul y Mitla, la Quebrada de Humahuaca abarca 171.116 ha.

Respecto a los tres bienes mixtos de esta región (tabla 7), ninguno está reconocido como paisaje cultural, aunque los tres cuentan con una dimensión territorial y paisajística que no precisa argumentación; si sus candidaturas hubieran sido propuestas después de 1992, seguramente lo habrían sido como paisajes culturales. Tienen

\section{TABLA 7. BIENES MIXTOS DE AMÉRICA LATINA Y EL CARIBE}

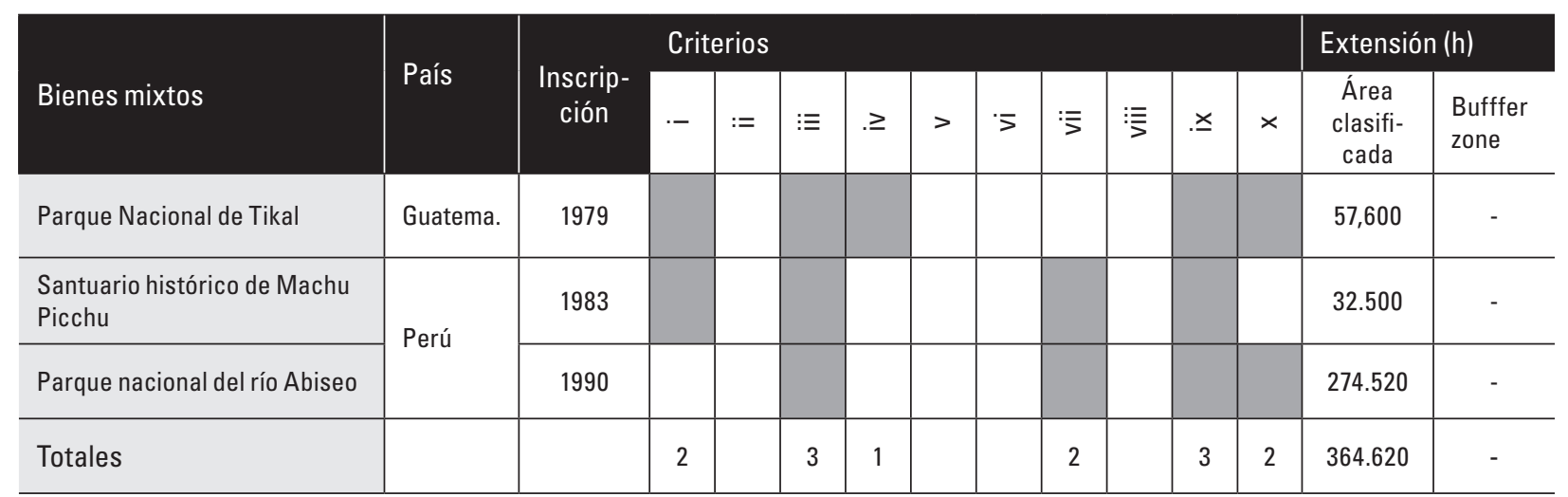

* En sombreado, los criterios por los que han sido reconocidos los bienes mixtos.

Fuente: Unesco 2013a y elaboración propia 
en común una superficie extensa, especialmente el Parque Nacional del río Abiseo en Perú, y los criterios iii y el ix se repiten en todos ellos, de lo que se deduce que son valorados como testimonio de una civilización, en estos casos ya desaparecida, y que son ejemplos notables de procesos naturales. Ninguno tiene zona de amortiguamiento (buffer zone), recurso que mejoraría su protección.

\section{Conclusiones}

\section{RESPECTO AL TRINOMIO PAISAJE, PATRIMONIO Y TERRITORIO}

A partir de la conceptualización del paisaje de organizaciones internacionales (Unesco, Consejo de Europa) y de la amplia producción bibliográfica sobre este recurso territorial, se han trabajado, desde una cierta deconstrucción, las complejas relaciones entre paisaje, patrimonio y territorio. Ello ha permitido una aproximación novedosa al conocimiento de los paisajes patrimoniales.

Las tendencias actuales de la praxis patrimonial pasan por la inevitable reconsideración de los territorios en los que se ubican los bienes culturales. Sin esta premisa, ni su preservación, gestión o aprovechamiento como recurso social están asegurados. Más importancia reviste esta cuestión respecto a los paisajes patrimoniales, en los que la dimensión territorial les es consustancial. Estos paisajes se corresponden con unidades territoriales complejas que, junto a elementos patrimoniales de muy distinta consideración, incluyen otros elementos que deben ser considerados y gestionados atendiendo a la preservación global de sus valores y en pro de la consecución de un desarrollo territorial integrado; la gestión resulta crucial, a este respecto, pero sobre ella no se ha avanzado suficientemente.

\section{RESPECTO A LA LISTA Y SUS PAISAJES CULTURALES}

La Lista es el registro de bienes patrimoniales de mayor reconocimiento y alcance planetario, muchos de los cuales tienen una proyección espacial compleja, por lo que este registro se convierte en un interesante laboratorio para la identificación, protección y gestión de los paisajes patrimoniales. La Lista identifica específicamente estos paisajes (paisajes culturales), pero también reconoce otros bienes que comparten esa proyección espacial compleja; especialmente los llamados bienes mixtos.

Tras varios decenios de gestión, de la Lista pueden inferirse numerosos aspectos positivos: corresponsabilidad internacional en la defensa del patrimonio; aportación de un corpus conceptual y metodológico; reforzamiento de la visibilidad del patrimonio y de sus posibilidades para el desarrollo socioeconómico, etcétera. La Lista es hoy, antes 
que nada, un registro prestigioso en los ámbitos académicos, políticos y ciudadanos. Sin embargo, su desarrollo también ha generado problemas no resueltos, especialmente conceptuales. Este artículo llama la atención sobre la necesaria clarificación terminológica, conceptual y operativa del lenguaje de Unesco respecto a sus paisajes culturales y cómo preservarlos y gestionarlos. Ello es una tarea compleja y falta de definición, empezando por la propia denominación, ya que todos los paisajes son culturales; y también por la insuficiente consideración de Unesco de la gestión de los paisajes culturales, que si bien se contempla como requisito previo y sine qua non para la inscripción de nuevos bienes, luego no se afina en qué debe significar esa gestión según la disparidad de paisajes culturales de la Lista y sus diferentes contextos socioeconómicos y territoriales.

\section{RESPECTO A LA SITUACIÓN DE LOS TERRITORIOS Y PAISAJES CULTURALES DE AMÉRICA LATINA Y EL CARIBE EN LA LISTA}

La presencia de bienes en la Lista de esta región es media-baja. Sea por desinterés o por problemas técnicos y políticos para preparar candidaturas, no puede decirse que en esta región se hayan establecido estrategias continuadas de sus estadosparte para reforzar su presencia en ella; como sí lo han hecho muchos países del planeta. Sólo México y, en menor medida, Brasil, escapan algo a esta lógica. Hay bastantes estados-parte sin bienes (dos de cada diez) o con tres o menos (dos de cada tres). Ello puede interpretarse como cierta renuncia a la puesta en valor de un recurso patrimonial de primer orden y como una cortapisa para el desarrollo de los territorios. Existe un margen de crecimiento de la región en relación con el objetivo de representatividad geográfica que no está siendo suficientemente utilizado. A título de ejemplo, 32 de los 33 territorios de América Latina y El Caribe no han incorporado ningún bien a la Lista en los últimos diez años, lo que contrasta abiertamente con el número de territorios y bienes de las listas indicativas (un total de 188 propuestas repartidas entre 30 territorios).

Este artículo ofrece algunas claves para superar esa situación atendiendo a las circunstancias de América Latina y El Caribe respecto a las prioridades establecidas por Unesco para incorporar nuevos bienes a la Lista. A este respecto, la subregión del Caribe no puede ser considerada subrepresentada frente a otras zonas del planeta, sino más bien lo contrario; aun así, Unesco le otorga prioridad porque en su planteamiento la representatividad no significa una distribución espacial equilibrada de bienes, sino en relación con el número de estadosparte. Es una representatividad más política que geográfica. Es por ello por lo que son mejor recibidas las propuestas de estados-parte minúsculos, como algunas de las islas caribeñas o del Pacífico frente a las de Brasil o Argentina, países en los que,

ARTÍCULO: Los paisajes culturales de Unesco desde la perpectiva de AméricaLatina y el Caribe. Conceptuaciones, situciones y potencialidad / Rocio Silva Pérez, Victor 
a pesar de tener una presencia relativamente baja en relación con su superficie, ya se consideran representados al tener más de tres bienes en la Lista.

La confrontación de prioridades y territorios de América Latina y El Caribe ha permitido identificar claves y un listado específico para conocer qué estados-parte tendrían menos cortapisas para nuevas inscripciones en la Lista y se confirma que la figura de paisaje cultural puede resultar de gran interés para la región. Esto se sustenta en que se trata de una figura holística y adaptable, sintetizadora de la complejidad del patrimonio y territorialmente inclusiva; además, sirve como aglutinadora de bienes patrimoniales ya reconocidos mediante otras figuras, territorialmente dispersos y difíciles de gestionar. Se trata de una fórmula especialmente adecuada para la conciliación, en lo que respecta a las percepciones y los usos, del patrimonio reconocido por Unesco, que responde a un modelo de patrimonialización institucional, y al forjado desde abajo por parte de las comunidades locales siguiendo un modelo de patrimonialización participativa.

Actualmente, los paisajes culturales de América Latina y El Caribe no llegan a diez. Todos son de carácter evolutivo, fueron aceptados únicamente atendiendo a criterios culturales y ninguno es transnacional. Sus dimensiones son muy diferentes, derivadas de la ausencia de una orientación precisa por parte del Comité; y esto determina sus posibilidades de gestión. La diversidad de paisajes evolutivos (de carácter fósil, de raigambre agraria, mineros, urbanos, etcétera); sus diferentes inserciones territoriales y socioeconómicas (ámbitos rurales, metropolitanos, de concentración de actividades, económicamente deprimidos, etcétera); y la disparidad de sus extensiones superficiales ofrecen distintos escenarios respecto a las necesidades, problemas y presiones a los que se ven sometidos los paisajes culturales y que condicionan sus posibilidades de gestión. Desde esta perspectiva, un análisis socioeconómico pormenorizado de los paisajes culturales de América Latina y El Caribe podría ofrecer muchas claves para avanzar en el complejo debate sobre su gestión.

Por último, dados los valores paisajísticos que poseen, sería conveniente proponer al Comité el reconocimiento como paisajes culturales de los tres bienes mixtos de la región América Latina y El Caribe: Parque Nacional de Tikal, Santuario histórico de Machu Picchu y Parque Nacional del río Abiseo. Ello contribuiría a acrecentar los paisajes inscritos por criterios naturales y los paisajes asociativos, que ahora tienen poco peso. Menos perspectivas 
genera la categoría de paisaje urbano histórico. La más que previsible revisión de este concepto hace poco seguros los trabajos en expedientes basados en ella; lo que no obsta para que, en determinados casos, como lo fue en Río de Janeiro, pueda ser argüido como un tipo de bien poco presente y sea aprovechado en nuevas propuestas.

\section{Bibliografía}

ALONSO, Pablo. La transición al pos-productivismo: parques patrimoniales, parques culturales y ordenación territorial. [En línea]. Eure. 40(119): 217238, 2014. ISSN 0250-7161. Disponible en: http:// dx.doi.org/10.4067/S0250-71612014000100010

CARTA Iberoamericana del paisaje cultural. [En línea]. Encuentro de Paisajes Culturales. 2012. Disponible en: http://encuentrospaisajesculturales.wordpress.com

CASTILLO RUIZ, José. La dimensión territorial del patrimonio histórico. En: CASTILLO, José, ed.; CEJUDO GARCÍA, Eugenio, ed. y ORTEGA RUIZ, Antonio, ed. Patrimonio histórico y desarrollo territorial. Sevilla, España, Universidad Internacional de Andalucía. 2009. p. 26-71. ISBN 978-847993-093-6. Disponible en: http://dspace.unia. es/handle/10334/2428.

COUNCIL of Europe. Convenio europeo del paisaje, hecho en Florencia el 20 de octubre de 2000. [En línea]. Council of Europe. 2000. Disponible en:http://www.coe.int/en/web/landscape/ text-of-the-european-landscape-convention
FERNÁNDEZ RODRÍGUEZ, Carmen. La protección del paisaje. Un estudio de derecho español y comparado. Madrid, España, Marcial Pons. 2007. ISBN 978-84-9768-412-5.

FOWLER, Peter. World heritage cultural landscapes, 1992-2002: a review and prospect. [En línea]. En: CULTURAL landscapes: the challenges of conservation. París, UNESCO World Heritage Centre. 2003. p. 16-32. World heritage papers 7. Disponible en: http://whc.unesco.org/en/series/7/.

GALIMBERTI, Cecilia Inés. Paisaje cultural y región. Una genealogía revisitada... [En línea]. GeoGraphos. 4(54): 531-552, 2013. ISSN 21731276. Disponible en: http://dx.doi.org/10.14198/ GEOGRA2013.4.54.

GROS PUYUELO, Carmen. La relación "paisaje-turismo-desarrollo local": examen de su significado en publicaciones recientes de divulgación territorial. Revista de desarrollo rural y cooperativismo agrario. (6): 123-133. 2002. ISSN 1139-7748. Disponible en: http://cederul.unizar.es/revista/ num06/08.htm.

HERNÁNDEZ, José de Jesús; ROTMAN, Mónica Beatriz y GONZÁLEZ, Alicia Norma. Patrimonio y cultura en América Latina: nuevas vinculaciones con el estado, el mercado y el turismo y sus perspectivas actuales. México, Universidad de Guadalajara. 2010. ISBN 978-607-00-3333-9.

IKT y PAISAIA. Catálogo abierto de paisajes singulares y sobresalientes de la CAPV. Vitoria, Departamento de Medio Ambiente y Ordenación del Territorio del Gobierno Vasco, Dirección de Biodiversidad y Participación Ambiental. 2005. 
LUENGO, Ana, ed. y RÖSSLER, Mechtild, ed. Paisajes culturales del patrimonio mundial. Elche, Ayuntamiento de Elche. 2012. ISBN 978-84-92667-10-9.

MADERUEL0, Javier, ed. Paisaje y patrimonio. Madrid, Abada Editores. 2010. ISBN 978-84-96775-94-7.

MARTÍNEZ DE PISÓN, Eduardo. El paisaje: circunstancia, patrimonio, saber y representación. En: MARTÍNEZ DE PISÓN, Eduardo, ed. y ORTEGA, Nicolás, ed. Paisaje y patrimonio. Madrid, FDS/ UAM. 2013. ISBN 978-84-8344-354-5.

--- Cultura y ciencia del paisaje. [En línea]. Agricultura y sociedad. (27): 9-32. 1983. ISSN 0211-8394. http://www.magrama.gob.es/ministerio/pags/ biblioteca/revistas/pdf_ays/a027_01.pdf

MATA OLMO, Rafael; MEER, Antonia de y PUENTE, Leonor de la. Sustainable development and making of territory and everyday landscapes as heritage-an experience in the Cantabrian mountains. En: FERIA, José María, ed. Territorial heritage and development. The Netherlands, Taylor and Francis Group. 2012. p. 141-159. ISBN 978-0-415-62145-8

MUJICA, Elías. Paisajes culturales en el contexto de América Latina y El Caribe: conceptos, tipologías, casos, implicancias y retos. En: RÖSSLER, Mechtild, ed.; LEPEIGNÉ-COBO, Ana María, ed.; RÍOS, Mayra, ed. Paisajes culturales en mesoamérica. San José, Unesco. 2000. ISBN 9968-9424-1-3.

NOGUE, Joan. El retorno del paisaje. [En línea]. Enrahonar quaderns de filosofia. (45): 123-136. 2010. ISSN 2014-881X. Disponible en: http:// dx.doi.org/10.5565/rev/enrahonar.224.
--- Turismo, percepción del paisaje y planificación del territorio. [En línea]. Estudios turísticos. (115): 45-54, 1992. ISSN 0423-5037. Disponible en: http://www.iet.tourspain.es/img-iet/Revistas/ RET-115-1992-pag45-54-69870.pdf

OBSERVATORIO de la Sostenibilidad en España. Cultura, patrimonio y paisaje en la sostenibilidad local. En: SOSTENIBILIDAD local. Una aproximación urbana y rural. Madrid, OSE. 2008. p. 459-469. ISBN 978-84-8476-371-0.

OJEDA RIVERA, Juan Francisco. Lectura transdisciplinar de paisajes cotidianos, hacia una valoración patrimonial. Método de aproximación. [En línea]. Revista INVI. 28(78): 27-75. 2013. ISSN 0718-8358. Disponible en: http://dx.doi. org/10.4067/S0718-83582013000200002

ORTEGA VALCÁRCEL, José. El patrimonio territorial. El territorio como recurso cultural y económico. Ciudades: Revista del Instituto Universitario de Urbanística de la Universidad de Valladolid. (4): 33-48. 1998. ISSN 1133-6579.

PRIORE, Riccardo. Derecho al paisaje, derecho del paisaje. En: ZOIDO, Florencio, coord. y VENEGAS MORENO, Carmen, coord. Paisaje y ordenación del territorio. Sevilla, Junta de Andalucía, Consejería de Obras Públicas y Transportes. 2002. p. 92-99. ISBN 8480952938.

RÖSSLER, Mechtild. World heritage cultural landscapes. [En línea]. The George Wright forum. 17(1): 27-34. 2000. ISSN 0732-4715. Disponible en: http://www.georgewright.org/171rossler.pdf

revista invi № 85 / Noviembre2015 / Volumen N º 30: 181-214 211 
RÖSSLER, Mechtild, ed.; LEPEIGNÉ-COBO, Ana María, ed. y RíOS, Mayra, ed. Paisajes culturales en mesoamérica. San José, Unesco. 2000. ISBN 9968-9424-1-3.

TILLEY, Christopher. A phenomenology of landscape: places, paths, and monuments. Oxford, Berg. 1994. ISBN 978-1859730768.

UNESCO. World heritage list. [En línea]. World Heritage Centre. 2013a. Disponible en: http://whc. unesco.org/en/list/

--- Operational guidelines for the implementation of the world heritage convention. [En línea]. World Heritage Centre. 2013b. Disponible en: http:// whc.unesco.org/archive/opguidel3-en.pdf

--- Recomendación sobre el paisaje urbano histórico, con inclusión de un glosario de definiciones. [En línea]. UNESCO. 2011. Disponible en: http://portal.unesco.org/es/ev.php-URL_ID $=48857 \& U R L$ DO=DO_TOPIC\&URL_SECTION=201.html
--- Artículo 16 del orden del día provisional: informe periódico: el estado del patrimonio mundial en América Latina y el Caribe, 2004. [En línea]. World Heritage Centre. 2004. Disponible en: http://whc.unesco.org/archive/2004/whc0428com-16es.pdf

--- Convención sobre la protección del patrimonio mundial, cultural y natural. [En línea]. World Heritage Centre. 1972. Disponible en: http://whc. unesco.org/archive/convention-es.pdf

--- Recomendación relativa a la protección de la belleza y el carácter de los lugares. [En línea]. UNESCO. 1962. Disponible en: http://portal.unesco.org/ es/ev.php-URL_ID $=13067 \& U R L_{-}$DO $=$DO_ TOPIC\&URL_SECTION=201.html

--- Cultural landscapes. [En línea]. World Heritage Centre. s.f. Disponible en: http://whc.unesco.org/en/ culturallandscape/ 